\title{
A Solar-Powered Irrigation System for Conserving Water and Energy Consumption in Egypt
}

\author{
Mina Ashraf, M. M. Fouad, and Lamia A. Shihata
}

\begin{abstract}
Africa, with its highly growing population, is in need for environmentally-friendly solutions to meet its food and energy needs. Solar-operated irrigation systems can be used in Egypt where there is no source of electricity and limited access to water. The aim of this paper is to present energy and cost analysis for a simulation of a solar-powered pumping system in Egypt using HOMER software. Experimental work is also carried out, in the GUC campus, for a solar-powered irrigation system which conserves water and energy through the use of soil moisture sensor to regulate the pump flow. The excess energy from the PV is used to power electric loads. Results of the simulation show that the maximum energy generation and consumption occur during the summer season. The annual net energy purchased from the grid is $408 \mathrm{kWh}$ after applying the net metering system. The inverter has the highest initial capital and replacement costs. For the experiments, the irradiance values range from $270 \mathrm{~W} / \mathrm{m} 2$ to $1450 \mathrm{~W} / \mathrm{m} 2$ and the panel's temperature from $15{ }^{\circ} \mathrm{C}$ to $60{ }^{\circ} \mathrm{C}$. The power output from the $\mathrm{PV}$ panel ranges from $3 \mathrm{~W}$ to $30 \mathrm{~W}$ depending on the solar irradiance and ambient temperature. The proposed water pumping system proved to be feasible and successful in conserving water and energy in Egypt.
\end{abstract}

Index Terms-Powered irrigation, water conservation, energy conservation.

\section{INTRODUCTION}

The demand for alternative renewable sources of energy has increased due to the hazardous impact of fossil fuels leading to global warming as well as the depletion of such conventional energy sources [1]. Solar energy is one of the most abundant sources of energy worldwide [2]. Solar panels are now extensively used for running street lights, for powering water heaters, for domestic load purposes as well as for irrigation purposes [3]. Automatic irrigation system is usually designed to help in reducing the water usage and avoiding excess water pumping through the use of soil moisture sensors that detect water needs [4]. In order to meet the need for food in Africa, with its highly growing population, environmentally-friendly technologies and alternative renewable energy sources are required [5]. Solar powered automated irrigation systems can be used in farms where there is no source of electricity [6]. In this paper, a simulation for a solar-powered pumping system is proposed under Egyptian climatic conditions while taking into consideration the excess energy generated from the PV panel to power electric loads inside a farmhouse. The energy and cost analysis for the water-pumping system are presented.

Manuscript received July 15, 2019; revised October 8, 2019.

The authors are with Mechatronics Department, German University In Cairo, Egypt (e-mail:mina_ashraf97@hotmail.com).
Moreover, the work is extended to include an experimental automatic solar-powered irrigation system in Egypt.

\section{LITERATURE REVIEW}

The literature review discusses the previous studies that have proposed solar-irrigation systems either experimentally or through simulations. (Mariem et al., 2014) [7] simulated a photovoltaic water pumping system with MPPT using MATLAB Simulink. The results showed that the PV control, in response to changes in temperature and solar intensity condition, was achieved. (Kalamkar \& Sontake, 2016) [6] Presented different types of motors used in experimental irrigation systems. Results showed that brushless DC motors are better because of their high efficiency, low noise, compact size, high reliability and low maintenance requirements. Another study by (Yahyaoui et al., 2015) [8], used micro-controllers to control the irrigation system and reduce the battery usage. Results showed that the system fulfilled the irrigation water demand using the batteries only when needed. (Harishankar et al., 2014) [2] Goal was to conserve energy and reduce the use of water by managing the amount of water pumped according to the moisture condition. The automated system proved to optimize the usage of water and reduce the human intervention for farmers. (Khan et al., 2014) [9] investigated the feasibility of irrigation systems in Bangladesh by comparing the irrigation cost of 27 different crops using photovoltaic irrigation system and diesel. Results showed that the irrigation using solar panel for some crops is cheaper and lucrative compared to that of the diesel. Thus, the aim of this work is to simulate a solar-powered irrigation system in Egypt according to the soil needs while making use of the excess energy from the PV panels. Also, the aim is to proof the concept by using an experimental prototype of the solar-powered system and the electric loads.

\section{METHODOLOGY}

The Methodology section includes the simulations and experiments performed, the components used and the procedures.

\section{A. Simulations}

In this paper, a simulation for a solar-powered pumping system using HOMER software is proposed under Egyptian climatic conditions while taking into consideration the excess energy generated from the PV panel to power electric loads inside a farmhouse. The climate chosen is for Cairo, Egypt under which the simulations are performed.

The Schematic of the On-grid system done using HOMER 
is shown in Fig. 1. The components used in this simulation were: 295 Watts Mono-Crystalline PV panel, $1 \mathrm{KW}$ inverter, 15 Watts light (13 hours per day all year), 70 Watts fan working (13 hours per day for 6 months per year) and 98 Watts pump (two hours daily all year).

The PV and inverter were chosen to fulfill the requirements of a fan, LED light and the $98 \mathrm{~W}$ pump. The fan and light bulb are represented as one electrical load and their load profile is shown in Fig. 2. The pump is represented as a second load and its load profile is shown in Fig. 3.

\section{B. Simulation Procedure}

All the energy produced from the PV panel is sold to the grid. According to the power consumption of the pump and the electric loads, the energy is being purchased from the grid. The pump used in the simulation works for only two hours per day during the irrigation periods of the plant. During the periods where there is no irrigation, the excess energy from the PV panel is used to power-up the electric loads (fan and light). The prices of electricity used for buying from the grid is $0.013 \$$ and for selling to the grid is $0.040 \$$ based on the net metering prices of Egypt. After simulating the system, an experimental setup is built to test the solar-powered irrigation system under Egyptian climates.

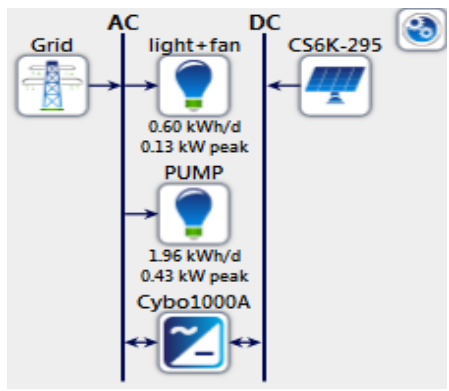

Fig. 1. Simulation schematic diagram.

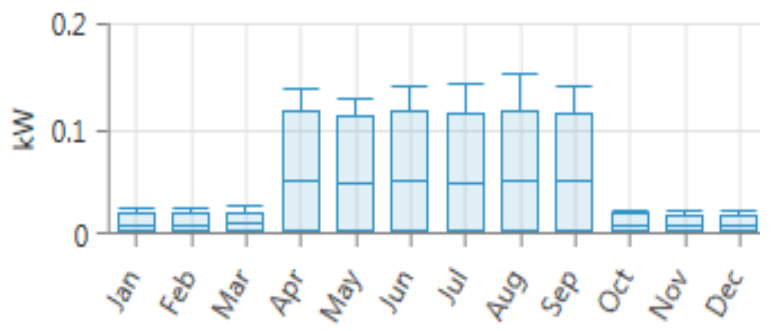

Fig. 2. Monthly load profile of Fan and Light bulb.

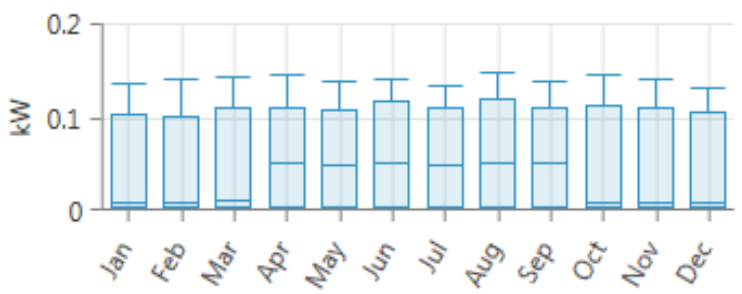

Fig. 3. Monthly load profile of the water pump.

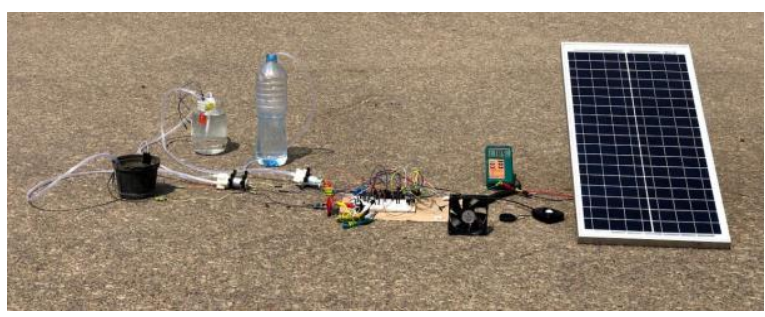

Fig. 4. Experimental setup.

\section{Experimental}

A prototype of a solar powered water pumping system for irrigation is proposed that aims to reduce the water consumption and make use of the excess electricity generation based on the plant irrigation schedule [10]. Readings were taken for a ten days period from 18th of March 2019 to 29th of March 2019 (excluding weekend days) in the German University Campus in Cairo, Egypt. Readings were taken each hour during the 10 days period from 10:30 am to $4: 30 \mathrm{pm}$ in terms of solar irradiance, panel's temperature, VOC and ISC of the PV panel, the pump voltage and current, the fan voltage and current, the LED voltage and current.

\section{Experimental Setup}

The experimental setup used for the solar-powered irrigation system is shown in Fig. 4. The setup consists of a $30 \mathrm{~W}$ polycrystalline silicon photovoltaic panel, two water pumps, two water tanks, a soil pot, a fan and a LED. A wooden frame is used to fix the PV panel at a tilt angle of $30^{\circ}$ (measured from the horizontal surface) as this is the optimal tilt angle of PV panels in Egypt [11], [12].

The measuring tools used during the experiments were: an infrared thermometer, a solar power meter and a multi-meter. A soil moisture sensor is used to measure the moisture content inside the soil and a water level sensor to keep track of the water level inside the tank. The electric connections consist of a breadboard, an Arduino Uno, a relay module, an $\mathrm{H}$-bridge, a 9 volt voltage regulator, a 5 volt voltage regulator, two switch buttons and electric wire connectors.

\section{E. Experimental Procedures}

The aim of the prototype of the solar-powered water pumping system is to irrigate the soil twice daily based on the amount of moisture inside the soil in order to reduce the excess water usage. Moreover, the excess energy generated from the PV panel during the no irrigation periods, is used to power up electric appliances simulating loads inside a farmhouse. This system aims to regulate the water usage and provide irrigation for crops which would generate food and simultaneously provide electricity supply for areas where there is no grid power in Egypt.

One $30 \mathrm{~W}$ polycrystalline PV panel is used to power up the irrigation system. First, a water source is used to fill the first tank using water pump number 1 until the water reaches the water level sensor fixed on top of the tank. Whenever the tank is full and the water level sensor signals the water, the water pump number 1 is stopped. The tank is then used to irrigate the soil pot twice daily using water pump number 2 . However, the quantity of water pumped for irrigation differs according to the readings obtained from the soil moisture sensor. The readings from the sensor differ each time due to the different weather conditions throughout the days. The water pump number 2 keeps pumping the suitable amount of water to the soil at 10:30 am until the soil moisture sensor reaches its maximum threshold value and the pump stops in return. After the irrigation, the tank needs to be re-filled with water so water pump number 1 automatically turns on to fill the tank. After the first irrigation is completed, the energy output of the PV panel is used to power-up appliances, i.e.: a 
$12 \mathrm{~V}$ fan and a LED light or if excess energy is available so it is supplied to the grid through a net-metering system. The fan and LED light are on only if the two pumps are off. The circuit is regulated using Arduino Uno, H-bridge and relay module. Afterwards, the second irrigation starts at 16:30 where readings from the soil moisture sensor are taken and accordingly the water is pumped with the suitable flow rate following the same procedures until the soil moisture sensor signals its maximum value.

\section{RESULTS AND DISCUSSIONS}

Results of the simulations and experimental work are presented in the following sections.

\section{A. Simulation results}

For each month, the amount of energy purchased (kWh), energy sold to the grid $(\mathrm{kWh})$, net energy purchased $(\mathrm{kWh})$, Peak demand $(\mathrm{kW})$ and Energy charge $(\$)$ are presented in TABLE I. Also, the amount of energy produced from the PV panels and from the grid for each month is shown in Fig. 5.

TABLE I: ENERGY AND COST ANALYSIS

\begin{tabular}{l|l|l|l|l|l}
\hline Month & $\begin{array}{l}\text { Energy } \\
\text { Purchased } \\
(\mathrm{kWh})\end{array}$ & $\begin{array}{l}\text { Energy } \\
\text { Sold } \\
(\mathrm{kWh})\end{array}$ & $\begin{array}{l}\text { Net } \\
\text { Energy } \\
\text { Purchased } \\
(\mathrm{kWh})\end{array}$ & $\begin{array}{l}\text { Peak } \\
\text { Demand } \\
(\mathrm{kW})\end{array}$ & $\begin{array}{l}\text { Energy } \\
\text { Charge } \\
(\$)\end{array}$ \\
\hline January & 14.2 & 28.4 & -14.2 & 0.387 & -0.570 \\
Februa-ry & 12.0 & 27.5 & -15.4 & 0.363 & -0.617 \\
March & 14.2 & 36.1 & -21.9 & 0.410 & -0.875 \\
April & 87.3 & 3.66 & 83.7 & 0.422 & 1.05 \\
May & 85.7 & 4.01 & 81.7 & 0.393 & 1.03 \\
June & 87.9 & 4.16 & 83.7 & 0.407 & 1.05 \\
July & 87.8 & 4.35 & 83.5 & 0.408 & 1.05 \\
August & 93.8 & 4.18 & 89.6 & 0.425 & 1.13 \\
Septem-ber & 88.0 & 3.59 & 84.4 & 0.399 & 1.06 \\
October & 14.1 & 33.4 & -19.4 & 0.414 & -0.774 \\
November & 13.9 & 28.5 & -14.6 & 0.403 & -0.584 \\
December & 14.5 & 27.0 & -12.5 & 0.378 & -0.5 \\
Annual & 613 & 205 & 409 & 0.425 & 2.46 \\
\hline
\end{tabular}

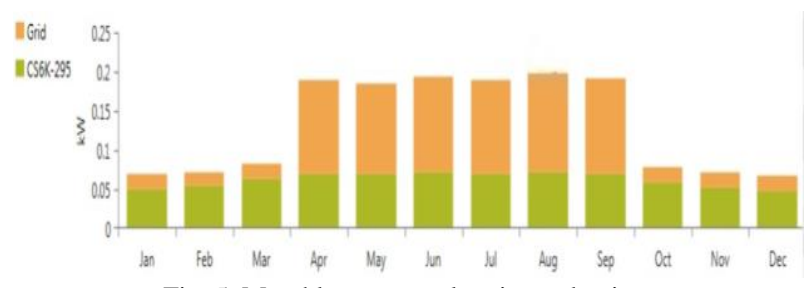

Fig. 5. Monthly average electric production.

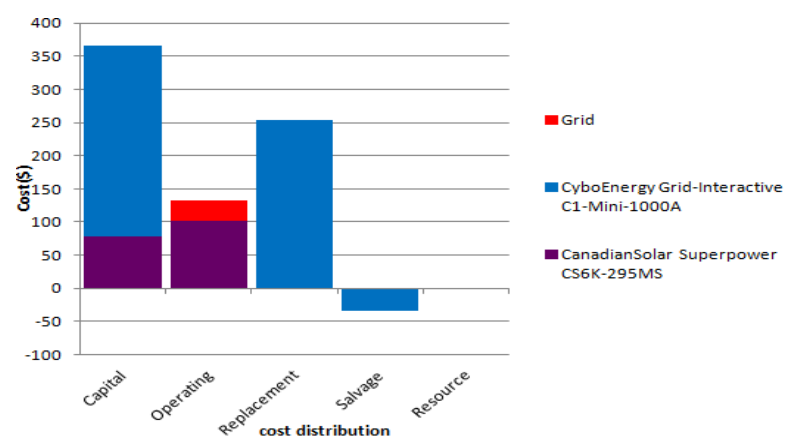

Fig. 6. Simulation cost analysis.
The amount of power generated from the PV panel during the summer season (April to September) ranges from $60 \mathrm{~W}$ to $90 \mathrm{~W}$ while during the winter season (October to March), the PV panel generates between $30 \mathrm{~W}$ and $50 \mathrm{~W}$. The rest of the electricity is obtained from the grid either during the afternoon periods, low solar intensity periods or during the periods of peak demand. TABLE I shows that during the summer season, the energy sold to the grid is much lower than the energy purchased from the grid during that interval and vice versa during the winter season. This can be attributed to the monthly profile in Fig. 2 and Fig. 3 where during the summer season, the total electric load is equal to the fan load, the LED load and the pump load while during the winter season, the total electric load is equal to the pump and LED loads only. The annual energy purchased from the grid is $613 \mathrm{kWh}$ while the annual energy sold is equal to 205 $\mathrm{kWh}$ with annual money spending of $2.46 \$$ after the net buying and selling of electricity to the grid during the year. Fig. 6 shows the cost analysis of the PV panel, the inverter and the grid. The initial capital and replacement costs of the inverter are the highest while the operating cost of the PV panel is the highest.

\section{B. Experimental Results}

Several calculations were conducted to calculate the FF and the power output from the PV panel at each instant. Measurements of the solar irradiance using a solar power meter and the surface temperature of the panel using infrared thermometer were taken every day from 10:30 to 16:30 for 10 days in GUC campus in Egypt. Fig. 7 shows the solar irradiance measurements versus time for each day. The direct and diffuse solar irradiance values 10 days period. It can be seen that the solar irradiance values are following a similar trend as readings were taken during the same season. The solar irradiance has a value of approximately $800 \mathrm{~W} / \mathrm{m} 2$ to $1000 \mathrm{~W} / \mathrm{m} 2$ during the morning periods and starts decreasing by the end of the day to reach $200 \mathrm{~W} / \mathrm{m} 2$ to $500 \mathrm{~W} / \mathrm{m} 2$. However, for Day2 and Day10, the weather was cloudy during some periods of the day and thus for example, the irradiance value for Day10 was in the range of $400 \mathrm{~W} / \mathrm{m} 2$ during the mid-day.

Fig. 8 shows temperature of panel with respect to time. The panel's surface temperature ranges between $15^{\circ} \mathrm{C}$ and $60{ }^{\circ} \mathrm{C}$ for the 10 days period. The panel's temperature reaches its peak value by the mid-day period and it can be seen that the lowest panel temperature values are obtained in Day2 and Day10 due to the clouds. Fig. 9 shows the power output from the PV panel at each hour for the 10 days. The power output ranges from $3 \mathrm{~W}$ during the very low solar irradiance values to $30 \mathrm{~W}$ during the very high solar irradiance values and intermediate temperature values as the increase in temperature reduces output by $10-25 \%$ [25]. The least panel output values are obtained on Day2 and Day10 when the solar irradiance was low.

Fig. 10 shows the pump voltage versus the analogue readings of the soil moisture sensor. The analog soil moisture sensor reads from 0 to 1032 which is then mapped through the arduino code to read from 0 to 255 according to the soil conditions. According to the analogue readings, the pump every time pumps different amount of water until the soil 
moisture sensor reads its maximum value. Also, a Pulse Width Modulation (PWM) technique is used to pump different flow rates with different voltages according to the soil needs to conserve water and energy. In Fig. 10, when the sensor reads 1032 (dry soil), the pump operates at its maximum allowable voltage from the regulator which is 9 volts. When the sensor reads an intermediate value like 313, the pump operates at an intermediate voltage of 3.64 volt. As for the fan, the current from the fan depends on the output from the PV panel at different time instants and ranged from 0.2 Ampere to 0.25 Ampere.

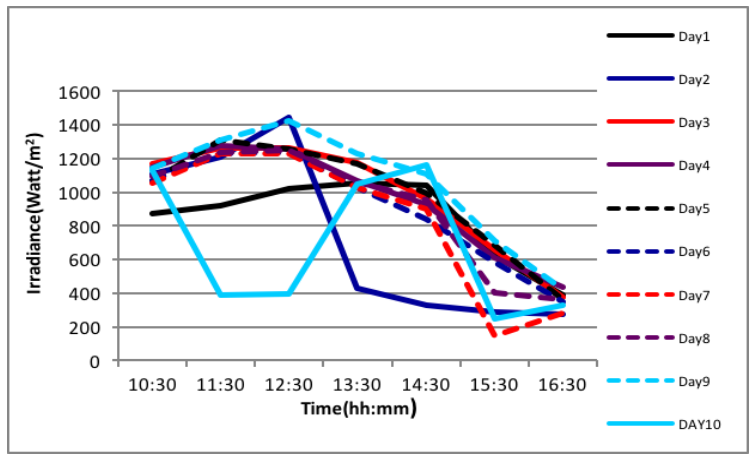

Fig. 7. Solar irradiance versus time.

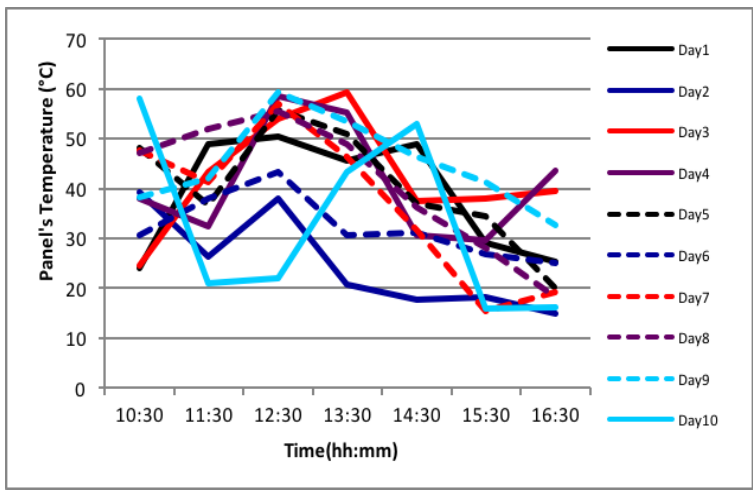

Fig. 8. Panel's temperature versus time.

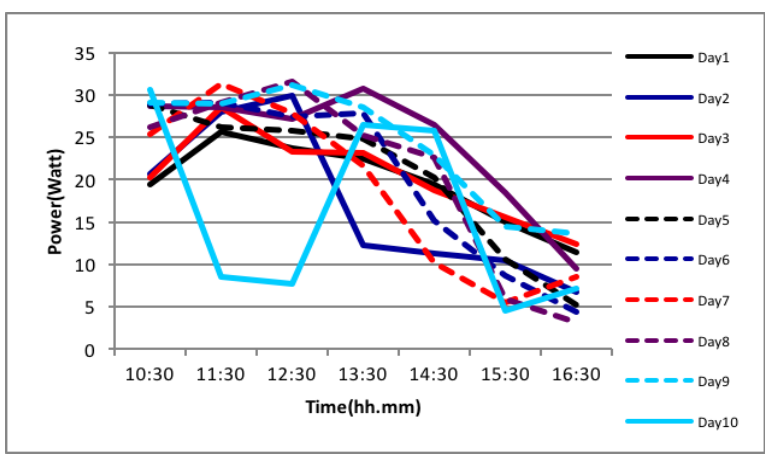

Fig. 9. PV Power output versus time.

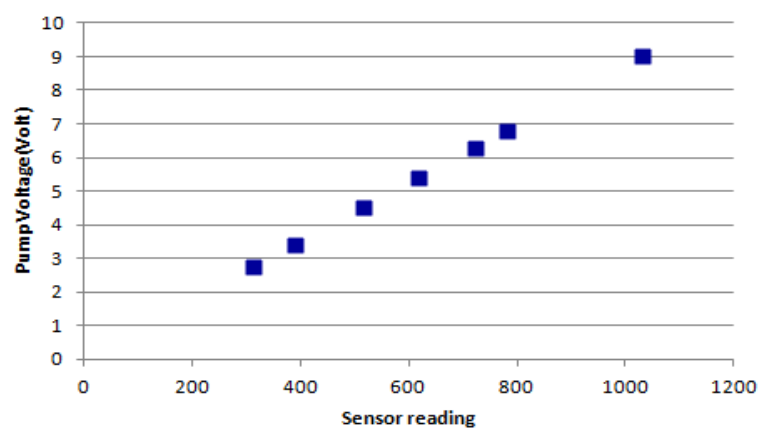

Fig. 10. Pump Voltage versus soil moisture sensor analog reading.

\section{CONCLUSIONS AND RECOMMENDATIONS FOR FUtURE WORK}

A simulation for a solar-powered water pumping system is proposed for irrigation purpose in Egypt using HOMER software. The irrigation system takes into consideration the excess energy generated from the PV panel to power some electric loads inside a farmhouse and to sell the excess energy to the grid using net-metering system. In addition, an experimental automatic solar-powered irrigation system in Egypt is proposed for a 10 days period in the German University Campus in Cairo, Egypt. The system works on conserving the water and energy consumption through the use of PWM and the use of soil moisture sensor to regulate the pump flow based on the water needs of the soil. The excess energy from the PV panel is used to power a fan and a LED. Results of the simulation showed that the PV panel generated the maximum power in summer while also the maximum energy consumed is during the summer season due to the fan, light and pump loads. The annual energy purchased from the grid is $613 \mathrm{kWh}$ while the annual energy sold is equal to $205 \mathrm{kWh}$ after applying the net-metering system. The inverter has the highest initial capital and replacement costs. For the experimental results, the solar irradiance values range from $270 \mathrm{~W} / \mathrm{m} 2$ to $1450 \mathrm{~W} / \mathrm{m} 2$ with some variations due to clouds. While the panel's temperature range between $15{ }^{\circ} \mathrm{C}$ and $60{ }^{\circ} \mathrm{C}$. The power output from the $\mathrm{PV}$ panels ranges from $3 \mathrm{~W}$ to $30 \mathrm{~W}$. The pump operates at different flow rates depending on the readings from the soil moisture sensor which conserves energy and water. The current from the fan depends on the output from the PV panel. The proposed water pumping system proved to be feasbile and succesful in conserving water and energy in Egypt. It is recommended for further studies to work experimentally on a bigger scale project with real electric loads. Also, it is recommened to apply optmization techniques to find the optimal conditions for the operation of the PV panel, the pump and the electric loads.

\section{REFERENCES}

[1] S. S. Chandel, M. N. Naik, and R. Chandel, "Review of solar photovoltaic water pumping system technology for irrigation and community drinking water supplies," Renewable and Sustainable Energy Reviews, vol. 49, pp. 1084-1099, September 2015.

[2] S. Harishankar, R. S. Kumar, K. P. Sudharsan, U. Vignesh, and T. Viveknath, "Solar powered smart irrigation system," Advance in Electronic and Electric Engineering, vol. 4, no. 4, pp. 341-346, 2014.

[3] V. B. Shinde and S. S. Wandre, "Solar photovoltaic water pumping system for irrigation: A review," African Journal of Agricultural Research, vol. 10, no. 22, pp. 2267-2273, May 2015.

[4] J. Uddin, S. T. Reza, Q. Newaz, J. Uddin, T. Islam, and J. M. Kim, "Automated irrigation system using solar power," in Proc. 2012 7th International Conference on Electrical and Computer Engineering, pp. 228-231, 2012.

[5] J. Burney, L. Woltering, M. Burke, R. Naylor and D. Pasternak, "Solar-powered drip irrigation enhances food security in the Sudano-Sahel," in Proc. the National Academy of Sciences, pp. 1848-1853, vol. 107, no. 5, 2010.

[6] V. C. Sontake and V. R. Kalamkar, "Solar photovoltaic water pumping system-A comprehensive review," Renewable and Sustainable Energy Reviews, vol. 59, pp. 1038-1067, June 2016.

[7] K. Mariem, K. M. Arbi, B. fredj Mouldi, and R. Habib, "Modeling and simulation of photovoltaic water pumping system," in Proc. 2014 International Conference on Electrical Sciences and Technologies in Maghreb (CISTEM), pp. 1-4, 2014.

[8] I. yahyaoui, M. Chaabene, and F. Tadeo, "Energy management for photovoltaic irrigation with a battery bank," International Journal of 
Energy Optimization and Engineering (IJEOE), vol. 4, no. 3, pp. 18-32, 2015.

[9] M. I. Khan, S. Sarkar, S. Hossain, A. U. Ahmed, and B. B. Pathik, "The feasibility study of solar irrigation: Economical comparison between diesel and photovoltaic water pumping systems for different crops," in Proc. 2013 International Conference on Electrical Information and Communication Technology (EICT), 2014, pp. 1-5.

[10] H. G. Jones, "Irrigation scheduling: Advantages and pitfalls of plant-based methods," Journal of Experimental Botany, vol. 55, no. 407, pp. 2427-2436, July 2004

[11] H. S. Hussein, G. E. Ahmad, and H. H. El-Ghetany, "Performance evaluation of photovoltaic modules at different tilt angles and orientations," Energy Conversion and Management, vol. 45, no. 15-16, pp. 2441-2452, September 2014.
[12] M. M. Fouad, L. A. Shihata, and E. I. Morgan, "An integrated review of factors influencing the perfomance of photovoltaic panels," Renewable and Sustainable Energy Reviews, vol. 80, pp. 1499-1511, December 2017.

Mina Ashraf was born in Cairo, Egypt. He is a student at the German University in Cairo, he got the bachelor degree in the Faculty of Mechatronics, German University in Cairo, Egypt, 2019. 